\title{
Nueva etapa de Trabajos de Prehistoria (2010 - 2013)*
}

\section{Ignacio Montero Ruíz \\ M. Isabel Martínez Navarrete}

Instituto de Historia, Centro de Ciencias Humanas y Sociales, CSIC. Madrid. ignacio.montero@cchs.csic.es, isabel.martinez@cchs.csic.es

\footnotetext{
*Este artículo aparece exclusivamente en la edición electrónica de Trabajos de Prehistoria.
}

1 La renovación de los Consejos de Redacción y Asesor de las publicaciones periódicas del CSIC tiene un ciclo de 4 años. Formalmente en julio de 2010 empezamos una nueva etapa en Trabajos de Prehistoria aunque, en realidad, los nuevos Consejos representan la continuación de una línea y política editorial que ha llevado a la Revista a una posición de reconocimiento y valoración internacional con su incorporación en 2008 a las bases de datos de la ISI Web of Science (Thomson-Reuters) A\&HCI y SSCI (Vicent 2008) y, en 2009, a las de SCOPUS (Elsevier BD desde 2003) con unos excelentes primeros Factores de Impacto (2008-2009)

2 Una de nuestras prioridades es el mantenimiento de esta posición. Ello no significará un cambio en la política editorial de Trabajos de Prehistoria que seguirá centrada en la publicación en español, francés o inglés de temas de Prehistoria y Protohistoria de la Península Ibérica y de su entorno geográfico, así como de teoría y metodología arqueológica. Lo que da valor a la Revista es el mantenimiento de los estándares de calidad internacionales $y$, muy especialmente entre ellos, la práctica escrupulosa del sistema de evaluación por pares. Creemos que optar por una temática más generalista la haría perder su condición de referente dentro y fuera de la Península Ibérica en el ámbito citado.

3 La normativa impone la obligación de que algunos miembros de los Consejos cambien. Sin embargo la estabilidad conseguida en el Equipo editorial nos permite planificar la estrategia de la Revista a medio plazo. Nuestra labor será continuista, adaptándose a las nuevas posibilidades que los recursos electrónicos ofrecen al mundo editorial para mejorar la difusión de la investigación.

4 Uno de los retos pendientes es precisamente adoptar un sistema de gestión y de relación con los autores y evaluadores más eficaz a través del programa libre Open Journal System, eliminando el envío de textos originales y pruebas de imprenta en papel. Adaptaremos las normas de presentación de originales a los nuevos mecanismos, actualizando también el sistema de citas convencionales. Facilitamos en las normas para autores de la página web una hoja de estilo detallada para que puedan resolver las dudas formales antes del envío de sus manuscritos, así como los mapas normalizados y la plantilla para la composición de las ilustraciones.

5 Buscaremos aumentar la visibilidad de Trabajos de Prehistoria. Este año el equipo de Edición Electrónica de Revistas CSIC ha ampliado el archivo histórico de artículos de libre acceso, incorporando los volúmenes 55 a 59 (1998 a 2002). Por nuestra parte, 
suprimiremos desde el volumen 67 (2) 2010 el embargo a la consulta, facilitando el acceso sin restricciones a todo su contenido.

6 Otra de las novedades es la publicación de números monográficos, por decisión del Consejo de Redacción, siguiendo el criterio de otras revistas de impacto. Su gestión y evaluación seguirá el mismo proceso que las de los números ordinarios. De este modo el segundo número de 2010 estará centrado en la Arqueometalurgia de la Edad del Bronce europea. Recogerá una parte de las contribuciones realizadas al Congreso Archaeometallurgy: Technological, Economic and Social Perspectives in Late Prehistoric Europe, TESME, celebrado en Madrid (CCHS-CSIC), entre el 27-29 de noviembre de 2009 con motivo de la jubilación de Salvador Rovira Llorens.

7 Queremos mantener la calidad de los originales que se publiquen. Por ello a la evaluación externa se aplicará ahora el procedimiento doble ciego, manteniendo en secreto los nombres de los autores y los evaluadores, así como la institución a la que pertenecen.

8 El trabajo de los evaluadores y evaluadoras es imprescindible para mejorar la presentación escrita y gráfica de los artículos. En estos momentos en los que es posible publicar en la Web cualquier información, es más necesario que nunca contar con el criterio de expertos que garanticen al lector unos contenidos científicos. La Revista está en deuda con todos los colegas que desinteresadamente han contribuido a que Trabajos de Prehistoria haya conseguido su posición actual.

9 En esta etapa iniciamos también un procedimiento de revisión de estilo de los textos, bajo la supervisión de los propios autores. Este esfuerzo esperamos que redunde en beneficio de los lectores, y también de los autores, al buscar una mayor claridad expositiva y simplicidad en la sintaxis, con un estilo más directo. Como dijo Quevedo "Las palabras son como monedas, que una vale por muchas, como muchas no valen por una".

10 Finalmente queremos agradecer a la Unidad de apoyo a la Edición de Revistas del CCHS y al Departamento de Publicaciones del CSIC, especialmente a Ramón B. Rodríguez, responsable de la Edición Electrónica, la ayuda y asesoramiento prestado para la actualización de la Revista.

\section{REFERENCIAS}

Vicent, J.M. 2008: "Editorial". Trabajos de Prehistoria 65(2): 7-11.

http://tp.revistas.csic.es/index.php/tp/article/view/145/146 [acceso 8-11-2010] 